\title{
Experimental investigation of EM noise environment surrounding detector systems in Swedish railways
}

\author{
Å. Wisten, S. Niska, J. Ekman, D. Björklöf and J. Delsing
}

\begin{abstract}
The close environment of railway tracks is heavily polluted by electromagnetic noise from the railway system itself. The reliability of railway signalling, communication, and control systems depends on good immunity to electromagnetic noise. There are sometimes false detector signals indicating non-existing flat wheels and ghost trains. A possible reason for detector failures is interference by transient voltage peaks in the detector system. Thus characterisation has been made of the electromagnetic environment around the detector system located at the track. The investigation shows that the typical electromagnetic environment is a combination of broadband low-level noise, and rare fast transients of potentially harmful amplitudes.
\end{abstract}

\section{Introduction}

The environment of railway tracks is exposed to magnetic and electric fields from trains, the railway power supply systems, nearby electric power transmission lines [1], and also from other sources [2]. A general trend towards increasing traffic flow, higher speeds, more trains per hour, longer trains and heavier axle loads demands more powerful engines and stronger currents in the supply lines. Consequently the radiated and conducted electromagnetic emissions from railway systems are increasing over time [3, 4].

The high-frequency content of the emitted fields [5] is also increasing owing to new methods of motor control. On the other hand, the switching voltages of electronic systems are decreasing, which is a consequence of a general demand for lower power consumption, and faster switching frequencies. The combination of more sensitive electronic circuits [6], and stronger electromagnetic noise, containing higher frequencies, may make the railway system as a whole more sensitive [7]. Systems of traffic signalling are not only crucial for safe traffic, but also important for traffic efficiency. If anything goes wrong in the signalling systems, all lights should switch to red, which is safe, but can cause delays in the timetables. Although traffic signalling systems have very high reliability, there have been unexplained phenomena, which may have been caused by disturbance from passing trains [8]. Because of very high goals for reliability, a continuous programme of work is going on, aiming at the highest possible security [9].

An investigation has been made in order to characterise train-induced electromagnetic noise in electronic systems in the close neighbourhood of railway tracks. For this aim, measurements on detector systems for flat wheels, hot brakes and hot bearings have been performed. Measurements on the signalling system have not been carried out

\footnotetext{
(C) IEE, 2006

IEE Proceedings online no. 20050040

doi:10.1049/ip-epa:20050040

Paper first received 4th February and in final revised form 25th April 2005

The authors are with the Luleå University of Technology, EISLAB, Department of Computer Science \& Electrical Engineering, SE-97187 Luleå, Sweden

E-mail: jonas.ekman@1tu.se
}

due to the potential risks of harming important security functions. There are several reasons for choosing the detector systems for this investigation, for example:

- There have been false signals in detector systems, indicating passing axes and trains that did not exist, or just giving alarms for system down.

- It is important that the detector systems are so reliable that correct decisions can be made by the driver whether or not to stop a train and take a certain car out of operation.

- The cables used in the detector systems are of the same type as the cables used in the signalling system.

With the purpose of finding possible reasons for failing electronic systems in the railway environment, electromagnetic noise has been studied at two detector sites in northern Sweden. One detector site, Notviken, specialises in detecting flat wheels by means of strain gauge bridges. The other detector site, Sunderbyn, has two IR-detector systems: one for hot bearings and the other for locked brakes. The Notviken section is fed by a booster transformer (BT) system, while the section in Sunderbyn is powered by an autotransformer (AT) system. The electromagnetic noise at the detector sites was measured under winter and summer conditions.

\section{Swedish railway system}

\subsection{Power supply}

Swedish trains are powered by $16 \frac{2}{3} \mathrm{~Hz} / 16 \mathrm{kV}$ alternating voltage. The railway power network is fed from the main Swedish $50 \mathrm{~Hz}$ power lines by converter stations. The converter stations are typically rated $50 \mathrm{~Hz} / 6 \mathrm{kV}$ at the primary, and $16 \frac{2}{3} \mathrm{~Hz} / 2.5 \mathrm{kV}$ at the secondary. The secondary voltage of the converters is transformed to $16 \mathrm{kV}$ to fit the train voltage. The power rating of the converter stations is 10 or $5.8 \mathrm{MVA}$. The distance between converter stations is about $100 \mathrm{~km}$. The input voltage $16 \mathrm{kV}$ is applied between the contact line and one of the rails, the ground (S) rail. Therefore, the return current from the engine passes partly through the S-rail, and partly to the ground. To minimise the current in the ground, there are booster transformers every $5 \mathrm{~km}$, in the BT system, or in the AT system, about 
every $10 \mathrm{~km}$. These transformers are designed to make the current in the rail equal to the current in the contact line (primary winding: contact line current; secondary winding: rail current). The BT system prevails in Sweden as a whole, but the modern AT system is installed at the ore track in northern Sweden, at the Öresund bridge to Denmark, and in parts of the western high-speed line. The AT system is fed with $32 \mathrm{kV}$ from the converters, between the contact line at $+16 \mathrm{kV}$ and a support line at $-16 \mathrm{kV}$, suspended at the poles, all along the track. The S-rail, i.e. the ground, is connected to the midpoint between +16 and $-16 \mathrm{kV}$, which makes the train voltage still $16 \mathrm{kV}$, as it is in the BT system. The other rail, the so called I-rail, is divided into isolated sections, each section set at a $6 \mathrm{~V}$ DC voltage. The purpose of this arrangement is to detect the positions of the trains, i.e. traffic monitoring [8]. The wheel axes make short circuits between the S-rail and the I-rail, lowering the voltage of the I-rail to zero. A section where a train is located has zero voltage on the I-rail, while other sections have $6 \mathrm{~V} \mathrm{DC}$. Thus the position of the train is defined for the traffic control centre.

\subsection{Detector systems for flat wheels, hot bearings and hot brakes}

The principle for flat wheel detectors is that imperfect wheels give hard hits to the rail, which can be detected by strain gauges fixed on the rail. Strain gauges are set up in systems of Wheatstone bridges, covering a length of about $3 \mathrm{~m}$ of both rails. Each Wheatstone bridge is connected to two wires for the DC power supply, and two wires for measuring the voltage at the balance points of the bridge. The DC power supplies and the evaluation units are located indoors in a measurement shed, a few metres away from the track. The wiring from the strain gauge bridges is packed together in a tube leading to the rack indoors. The wiring distance is $6-10 \mathrm{~m}$, see Fig. 1, depending on the position of the strain gauges. The detector for hot bearings is mainly a

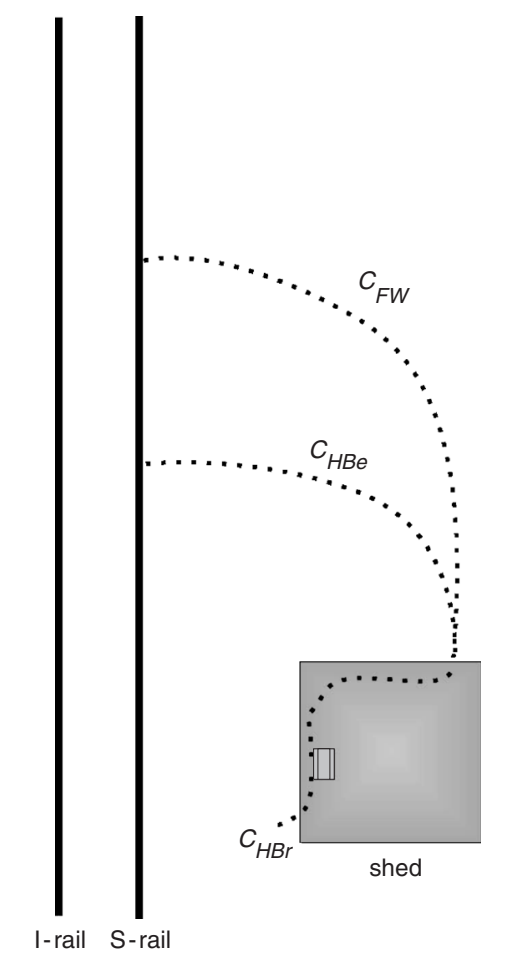

Fig. 1 Measurements on detector transients performed inside shed Detectors connected to evaluation units inside shed by coaxial cables (RG223). Cabling for flat wheel $\left(C_{F W}\right)$, hot bearing $\left(C_{H B e}\right)$, and hot brakes $\left(C_{H B r}\right)$ detector systems distance temperature reading unit, an IR detector at ground level, aiming upwards towards the passing wheel bearings. A mechanical lid protects the optics when no train is passing. The information and control signals are transported using shielded cables, type Belden $1250 \mathrm{~A}$ [10], with the main unit indoors, about $10 \mathrm{~m}$ away. The detector for hot brakes is also mainly a distance IR meter, monitoring the outer rim of the passing wheels. In this case the cabling to the indoor evaluation unit is shorter.

\section{Measuring methods}

The electromagnetic environment in the neighbourhood of the railway track has been investigated by means of antennas, cables in the terrain and stationary equipment in the detector systems of flat wheels, dragging brakes and hot bearings. Two detector sites in northern Sweden have been thoroughly examined: Sunderbyn and Notviken, site characteristics of which are given in Table 1.

\section{Table 1: Description of measurement sites}

\begin{tabular}{lll}
\hline Site & Sunderbyn & Notviken \\
System & AT & BT \\
& $\pm 16 \mathrm{kV}, 16 \frac{2}{3} \mathrm{~Hz}$ & $16 \mathrm{kV}, 16 \frac{2}{3} \mathrm{~Hz}$ \\
Detectors & Hot brakes & Flat wheel \\
& Hot bearings & \\
Misc. & Parallel HV power lines & \\
\hline
\end{tabular}

Two types of engines have been selected for thorough examination: The freight train engine $\mathrm{RC} 4$ and the engine of the 6000 tonne ore trains, the heavy DM3. Electromagnetic fields from passing trains influencing measuring devices and cabling systems have been investigated by means of standard cables, used as antennas, set up close to the track, and by recording signals in stationary equipment for detecting flat wheels, hot bearings and dragging brakes.

\subsection{Description of measuring site}

The evaluation units of the detector systems are installed in small houses close to the railway track, the nearest wall being about $3 \mathrm{~m}$ from the nearest rail. The walls and roofs of these sheds have aluminium shielding, in order to reduce electromagnetic interference of the equipment inside. Our measuring instrumentation was set up inside the same sheds.

To register transients occurring in the detector systems, measurements were carried out inside the shed by connecting the measuring equipment directly to the evaluation units of the detector systems. The evaluation units are connected to each detector system by means of RG223 cables according to Fig. 1.

To be able to separate conducted and radiated transients, the detector system measurements were completed with a cable setup using shielded cables, type Belden 1250A, with two twisted pairs. The twisted pair receiving cables were set up parallel to the rails, at 1,3 and $6 \mathrm{~m}$ distances from the nearest rail, at the same height as the upper level of the rails. At the far end, each twisted pair was loaded with $150 \Omega$ resistors, weather-protected and electrically shielded. While testing for finding best possible locations, cable locations in the middle of the track and very close to one rail were also evaluated, but later not used, because of too low signal levels. A few tests with $15 \mathrm{~m}$ Belden-cables starting at a distance of $6 \mathrm{~m}$ from the rail, and running at 45 and $90^{\circ}$ 
angles to the track were also tested, but not further used owing to very low signal levels. The cable locations are detailed in Fig. 2. Each part of the twisted pairs was connected to the centre conductor of a $10 \mathrm{~m} \mathrm{RG} 223$ cable that was running through specially made aluminium lids covering the window openings of the shed. The indoor length of the RG223 coaxial cables was $2.3 \mathrm{~m}$, giving a total length of $12.3 \mathrm{~m}$. Measurements were carried out using a Tektronix TDS 7254, 2.5 GHz, four channel, 32 Mbyte,

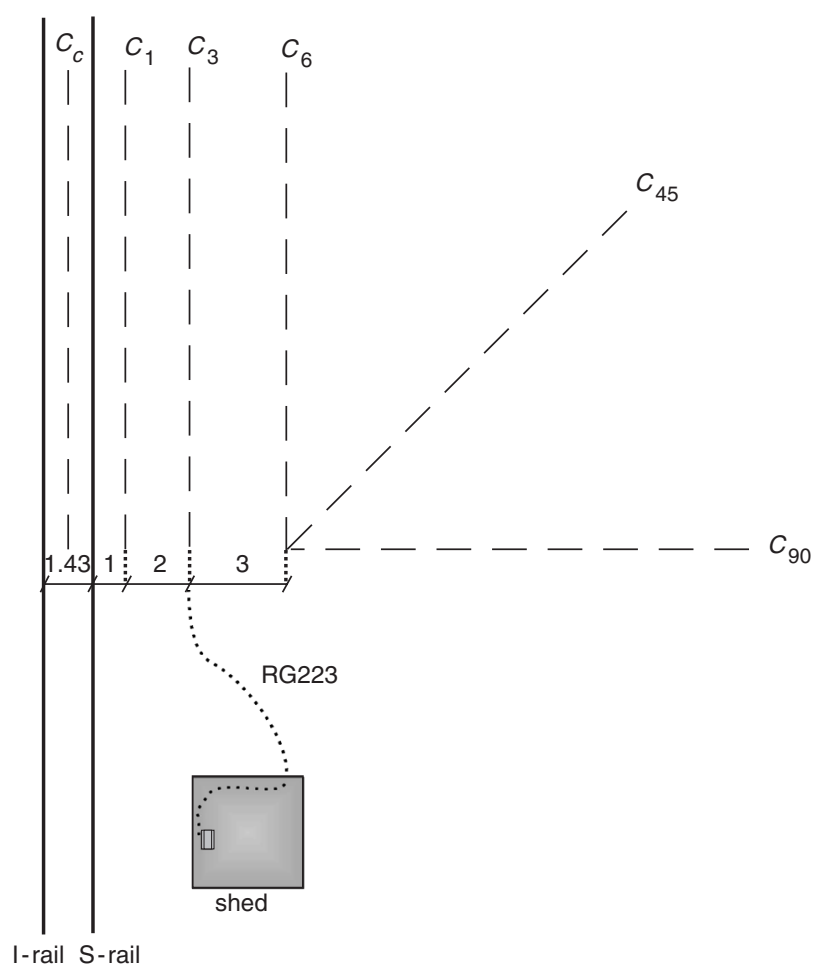

Fig. 2 Measurements to detect radiated disturbances performed using parallel Belden $1250 \mathrm{~A}$ cables contacted by RG223 cables

Cable locations in middle of track $\left(C_{C}\right)$, parallel to rails at $1 \mathrm{~m}\left(C_{1}\right)$, $3 \mathrm{~m}\left(C_{3}\right)$, and $6 \mathrm{~m}\left(C_{6}\right)$ distances from nearest rail, and cables starting at distance of $6 \mathrm{~m}$ from the rail, and running at $45^{\circ}\left(C_{45}\right)$ and $90^{\circ}\left(C_{90}\right)$ angles to track also tested. Distances in metres oscilloscope, inside the shed, where the common-mode voltages of each part of a twisted pair could be recorded. The differential mode voltages were calculated by subtracting the two common-mode voltages of a twisted pair.

\subsection{Description of measurements performed}

Earlier [11] measurements indicate that the power densities of frequencies above $500 \mathrm{MHz}$ are relatively low. Based on this, the main efforts have been concentrated to the frequency interval $0-500 \mathrm{MHz}$. Initial experiments showed very clear evidence that potentially harmful signal energy is located in the frequency range below $10 \mathrm{MHz}$. Thus it was decided to use a $50 \mathrm{MHz}$ sampling rate. In addition to this, some tests were made with $5 \mathrm{GHz}$ sampling rate to catch higher frequency disturbances. All measurements was made with a Tektronix TDS7254 having a maximum sampling rate of 20 GSamples/s and a memory depth of 32 Mbyte.

A summary of the performed measurements, the conditions and the equipment used can be found in Table 2 .

\section{Results}

This Section presents results for two cases. First, measurements are presented when no train is present. Secondly, measurements for actual train passages are presented. The last part presents box plots for a two-day measuring period for each detector system.

\subsection{No train passage}

Measurements presented below detail transients recorded by the measuring equipment when no train is present, approaching or leaving the measuring site, i.e. trains are more than $1 \mathrm{~min}$ away, corresponding to $>800 \mathrm{~m}$ away for slowest train type:

(a) Flat wheel detector system and parallel cable setup: First, a $90 \mathrm{~s}$ measurement on one flat wheel detector in Notviken is shown in Fig. 3, together with measurements on a parallel passive cable in Fig. 4. At least one recorded transient, seen around $18 \mathrm{~s}$, at the flat wheel detector is also seen at the passive cable indicating radiated electromagnetic disturbances.

Table 2: Description of actual measurements

\begin{tabular}{|c|c|c|c|}
\hline Measurement object & Conditions & Equipment & Sampling \\
\hline Flat wheel detector system & & $\begin{array}{l}2.3 \mathrm{~m} \mathrm{RG} 223 \text { (indoors), } \\
7.0 \mathrm{~m} \text { shielded, double pairs } \\
\text { (outdoors) }\end{array}$ & $50 \mathrm{M}$ samples/s-5 G samples/s \\
\hline Fig. 1, $C_{F W}$ & $\begin{array}{l}\text { No train, Fig. } 3 \\
\text { DM3, } 3 \times 500 \text { A, Fig. } 7\end{array}$ & & \\
\hline Fig. 1, $\mathrm{C}_{H B e}$ & $\begin{array}{l}\text { No train, Fig. } 6 \\
\text { RC4, idle, Fig. } 10\end{array}$ & & \\
\hline Hot brakes detector system & & 2.3 m RG223 (indoors) & $2.5 \mathrm{k}$ samples/s-50 M samples/s \\
\hline Fig. 1, $\mathrm{C}_{\mathrm{HBr}}$ & $\begin{array}{l}\text { No train, Fig. } 5 \\
\text { RC4, idle, Fig. } 9\end{array}$ & & \\
\hline Parallel cable setup & & $\begin{array}{l}2.3 \text { m RG223 (indoors), } \\
10.0 \text { m RG223 (outdoors) }\end{array}$ & $2.5 \mathrm{k}$ samples/s-50 M samples/s \\
\hline Fig. $2, \mathrm{C}_{3}$ & $\begin{array}{l}\text { No train, Fig. } 4 \\
\text { DM3, } 3 \times 500 \text { A, Fig. } 8\end{array}$ & & \\
\hline
\end{tabular}




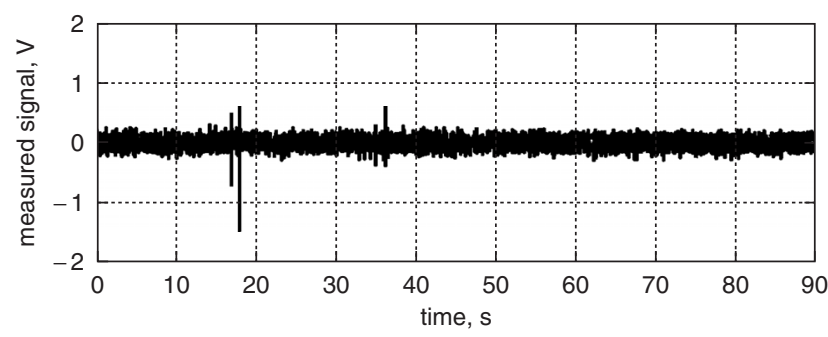

Fig. 3 Measured signal on flat wheel detector for $90 \mathrm{~s}$

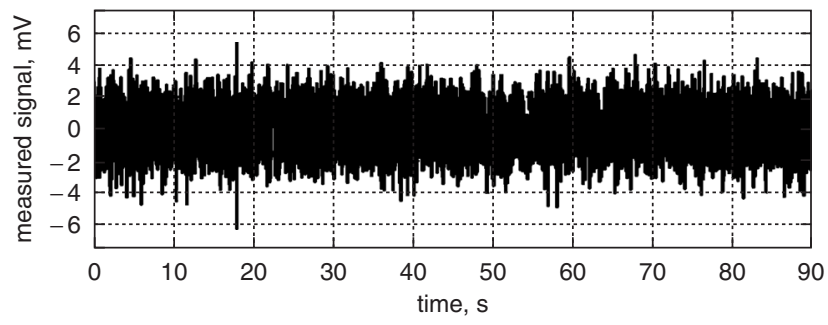

Fig. 4 Measured signal on parallel passive cable $3 \mathrm{~m}$ from track for $90 \mathrm{~s}$

(b) Hot brakes detector system: Secondly, measurements on the hot brakes detector system in Sunderbyn is presented in Fig. $5 a$ with a closeup of one large transient in Fig. 5b. Large transients of this type (Fig. 5) are often recorded by the measurement equipment when trains are absent.

(c) Hot bearings detector system: Finally, measurements on the hot bearing detector system are shown in Fig. $6 a$ with a closeup of one large transient in Fig. $6 b$. Although these measurements are performed in parallel to the hot brakes measurements shown in Fig. 5, the transients is not occur at the same time, indicating conducting electromagnetic disturbances.

\subsection{Train passage}

This Section presents typical measurement results from various train passages:

(a) Flat wheel detector system and parallel cable setup: First, a $10 \mathrm{~s}$ measurement on one flat wheel detector in

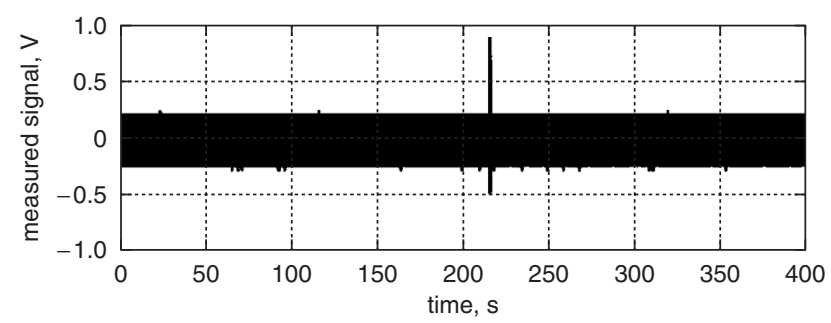

a

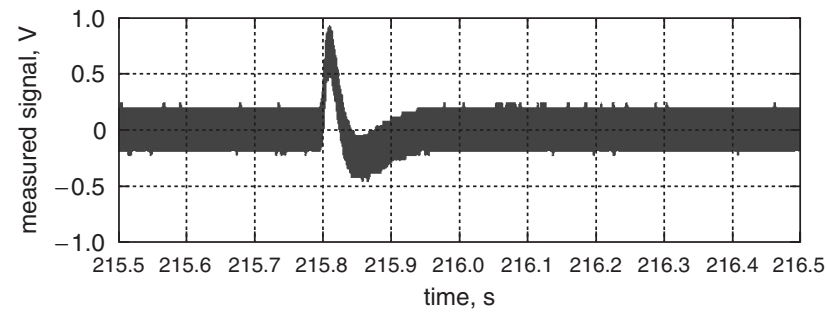

Fig. 5 Measured signal $a$ Hot brakes detector for $400 \mathrm{~s}$ $b$ Closeup for one transient

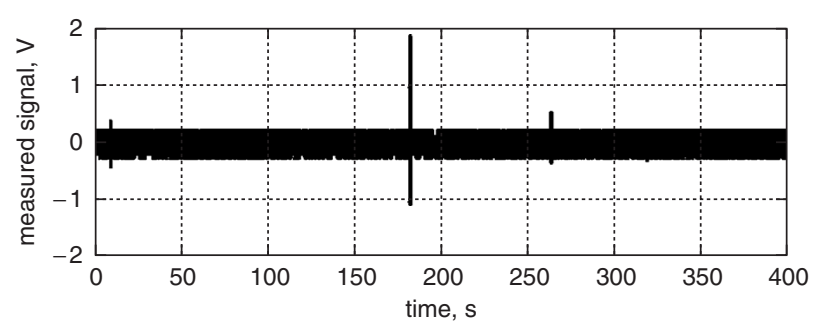

a

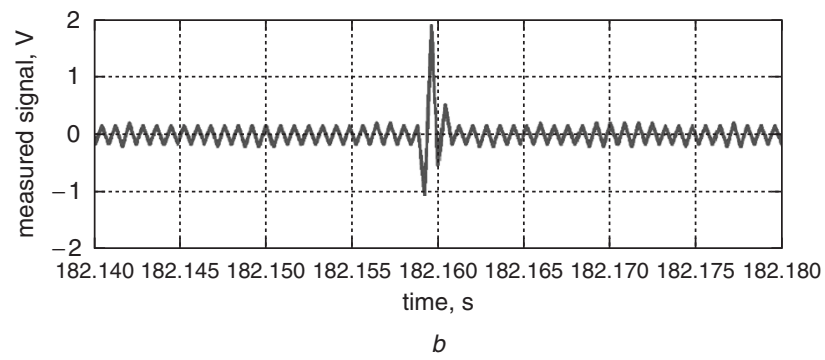

Fig. 6 Measured signal

$a$ Hot bearing detector for $400 \mathrm{~s}$

$b$ Closeup for one transient

Notviken is presented (Fig. 7) together with measurements on a parallel passive cable (Fig. 8). As for the background measurements in the previous Section, transients observed at the flat wheel detector are also found at the parallel cable $(0.365,0.721$, and $9.762 \mathrm{~s})$ indicating radiated disturbances. Further, the closeup in Fig. $7 b$ shows that the recorded transients, at the flat wheel detector system, are saturated at $\pm 5 \mathrm{~V}$, indicating the presence of larger transients.

(b) Hot brakes detector system: Secondly, measurements on the hot brake detector system are presented (Fig. 9). One transient at a fairly low magnitude $(85 \mathrm{mV})$ is visible at $15.23 \mathrm{~s}$. These results, indicating a relatively low disturbance on the hot brakes detector, are typical for the studied detector system.

(c) Hot bearings detector system: Finally, measurements during train passage on the hot bearing detector system are shown in Fig. 10a with a closeup of one transient in
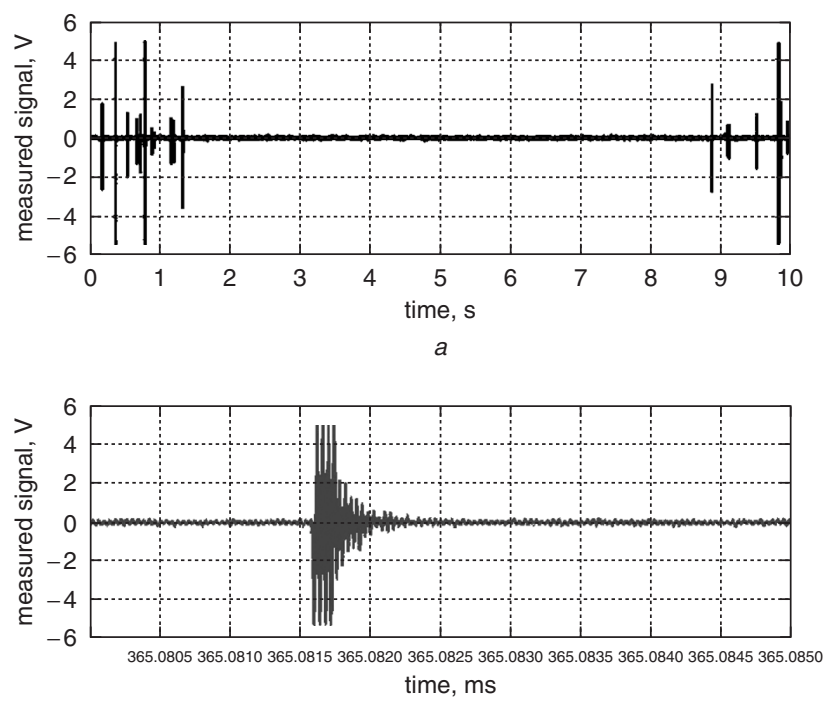

$b$

Fig. 7 Measured signal $a$ Flat wheel detector for $10 \mathrm{~s}$ $b$ Closeup for one transient 


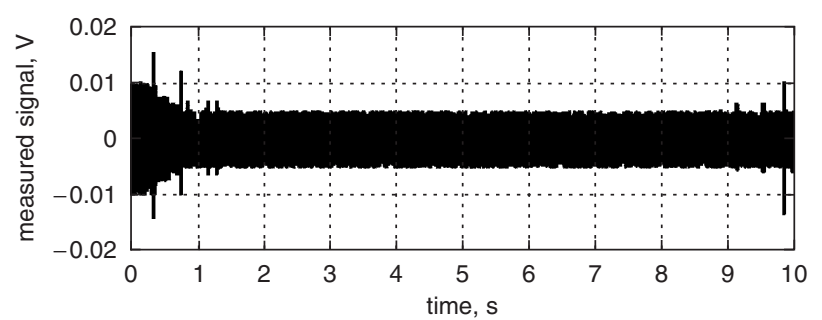

a

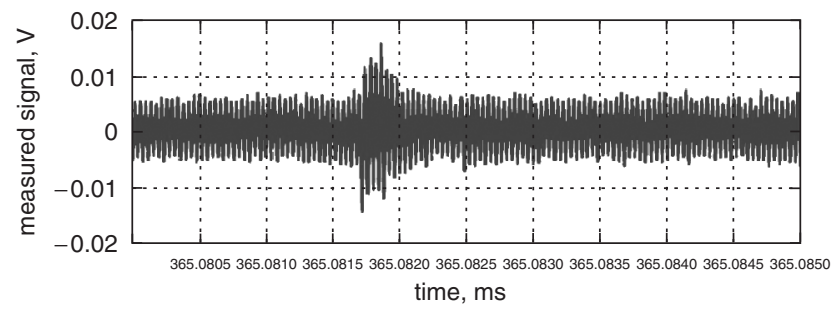

$b$

Fig. 8 Measured signal a Parallel passive cable for $10 \mathrm{~s}$

$b$ Closeup for one transient

Four peaks can be identified at same time in both cable and flat wheel detector (shown in Fig. 7a)

Transient at cable as shown in $b$ arrives $150 \mathrm{~ns}$ after same transient is seen at flat wheel detector in Fig. $7 b$

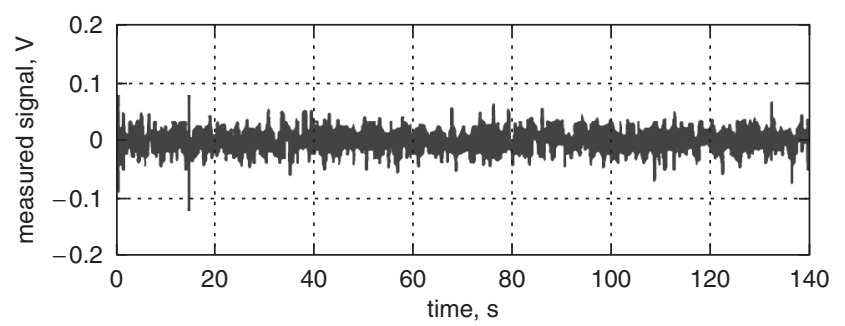

Fig. 9 Measured signal on hot brake detector for $140 \mathrm{~s}$

Fig. 10b. These measurements are performed in parallel to the hot brake measurements shown in Fig. 9 and some transients are recorded in both systems at the same time $(15.23 \mathrm{~s})$ indicating radiated electromagnetic disturbances. However, there are several large transients recorded in the hot bearing detector system that are not present in the hot brake detector system indicating both radiated and conducted electromagnetic disturbances. Further, the transient shown in Fig. $10 b$ is very similar (with regard to period) to transients resulting from the braking/closing of the line-pantograph system, as reported in [12].

\subsection{Typical disturbance levels for two-day period}

This Section presents boxplots [13] for typical disturbance levels measured at each detector system for a two-day period. The boxplot is convenient to visualise univariate data since it shows information about the location of the spread of the data by means of the median and the interquartile range. The boxes in Fig. 11 have lines at the lower, median, and upper quartile values for the measured detector voltages. The whiskers, dashed, on both sides of the boxes shows the skewness in the data. As in these measurements, the data is positively skewed (long upper tail) since large detector values are easy to separate from the low values that are mixed with the noise levels in the measurement systems (see Fig. 11).

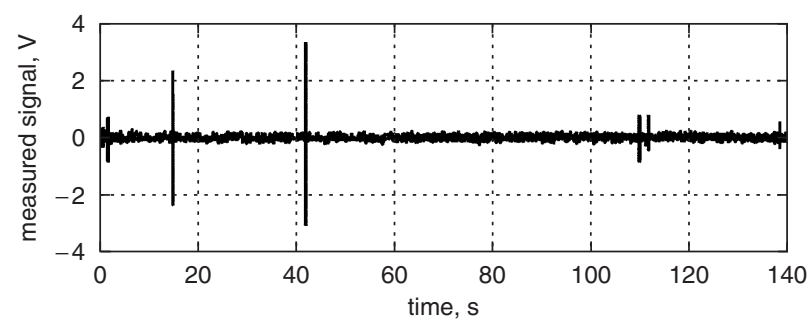

a

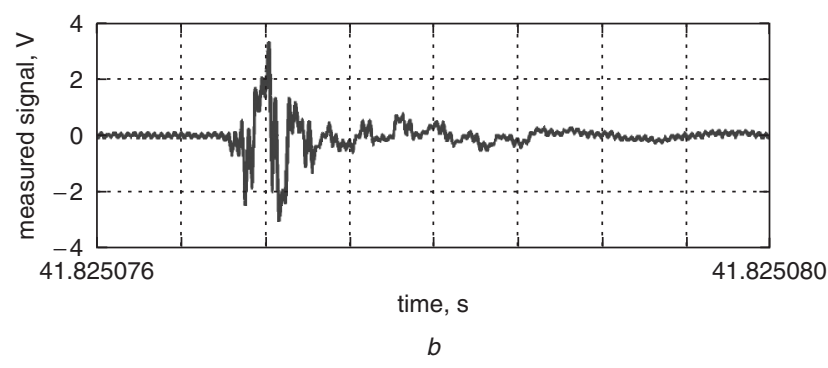

Fig. 10 Measured signal $a$ Hot bearing detector for $140 \mathrm{~s}$ $b$ Closeup for one transient
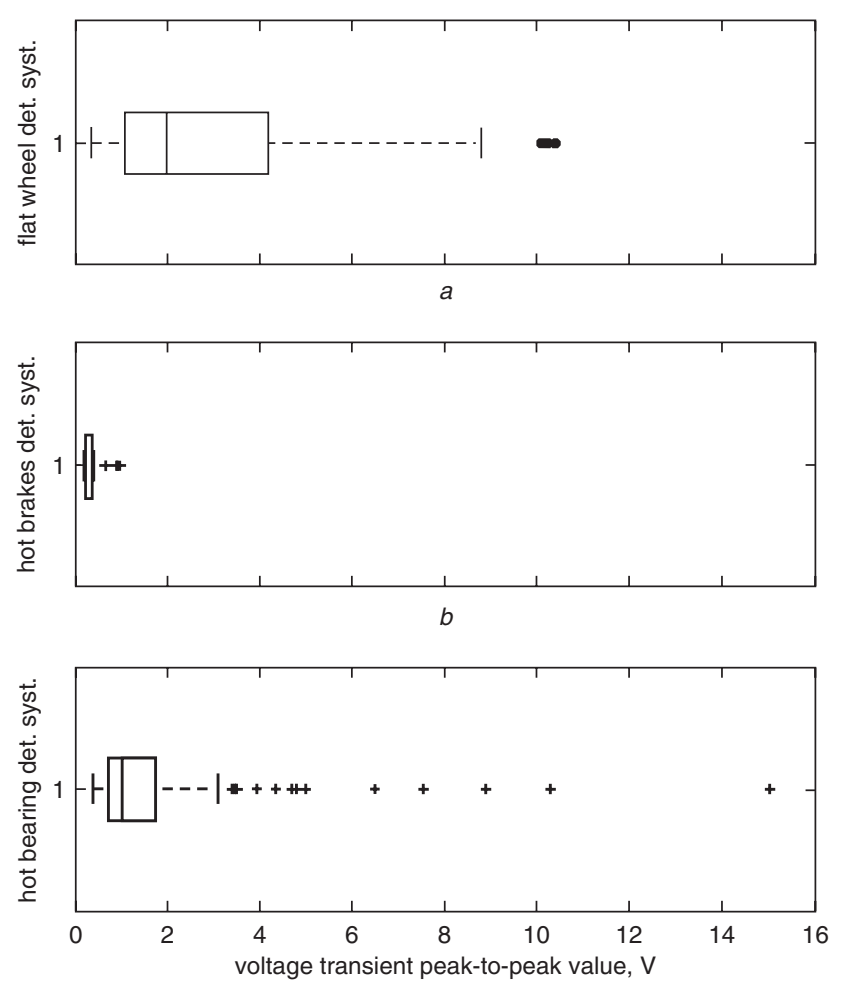

Fig. 11 Boxplot for measured signals for a two-day period $a$ Flat wheel detector system $b$ Hot brake detector system $c$ Hot bearing detector system

From the plots the following observations can be made:

(a) $25 \%$ of the measured transients are above $4.20 \mathrm{~V}$ for the wheel flat detector system (Fig. 11a)

(b) $25 \%$ of the measured transients are above $0.35 \mathrm{~V}$ for the hot bearing detector system (Fig. 11b)

(c) $25 \%$ of the measured transients are above $1.85 \mathrm{~V}$ for the hot bearing detector system (Fig. 11c).

Further, the wheel flat and the hot brake detector system have fewer outliners ('wild data') than the hot bearing detector system with measured transient peaks of $15.2 \mathrm{~V}$. 


\begin{tabular}{|c|c|c|c|c|c|c|}
\hline \multirow[t]{3}{*}{ Detector } & \multicolumn{6}{|c|}{ Situation } \\
\hline & \multicolumn{3}{|c|}{ DM3 engine with contact line current } & \multicolumn{2}{|c|}{ RC4 engine with contact line current } & \multirow[t]{2}{*}{ No train passage } \\
\hline & $113 \mathrm{~A}$ & $338 \mathrm{~A}$ & $450 \mathrm{~A}$ & $108 \mathrm{~A}$ & $237 \mathrm{~A}$ & \\
\hline Flat wheel (V) & 5.0 & 6.7 & 2.5 & 1.7 & 10.3 & 5.2 \\
\hline Hot brakes (V) & 1.0 & 1.0 & & 0.015 & 0.17 & 0.26 \\
\hline Hot bearings (V) & 4.2 & 4.0 & & 9.0 & 15.2 & 1.4 \\
\hline Parallel cable (V) BT & 0.015 & 0.029 & 0.017 & 0.017 & 0.019 & 0.009 \\
\hline Parallel cable (V) AT & 0.016 & 0.026 & & 0.01 & 0.016 & 0.11 \\
\hline
\end{tabular}

The measurements on the hot brakes detector system (Fig. 11b) confirm the conclusions from previous Sections showing maximal disturbance levels of $1.0 \mathrm{~V}$. Further, the hot bearing detector system (Fig. 11c) shows the largest disturbance levels close to $15.2 \mathrm{~V}$.

\subsection{Malfunction due to transient disturbances}

The examined detector systems indicate flat wheels, hot brakes, and hot bearings by a simple, damped sinusoidal signal [14]. The amplitude of the sinusoid gives the severity of the flatness or temperature. Since many of the voltage transients registered at the backplane of evaluation units have sinusoidal shape, the possibility for EMC problems to occur is high. However, the evaluation units only process information from the detectors while the train is present at the site. Thus, the presence of ghost trains can not be contributed to EMC problems in the investigated detector systems. However, if the sensors indicating the presence of trains are out of order, ghost trains might be indicated by the random voltage transients recorded (see Figs. 5-10).

\section{Discussion}

Voltage transients of substantial magnitude have been registered in detector systems close to the railway (see compilation in Table 3). A broad spectrum of frequencies within the transient pulses has been registered. Most transients show an oscillating behaviour. As a method of analysis, leaky dummy cables, which can receive radiated noise, can be set up in order to separate radiated electromagnetic emissions from conducted noise. The measurements show clearly that electromagnetic emissions from the line-pantograph system, electric discharges, light arcs at the contact line, and high-frequency emissions from the engine, at the very passing of the train, are not a direct threat to well built and installed detector systems [15]. According to our measurements, the signal-to-noise ratio is more than $40 \mathrm{~dB}$ in all cases (noise level of $10 \mathrm{mV}$ between twisted pairs, at the train passage) But, on the other hand, there are alarmingly high voltage peaks, having very short rise and fall times $\left(\sim 10 \mathrm{~V}_{\mathrm{pp}} / 20 \mathrm{~ns}\right)$, not necessarily when the train is close. These peaks are of the same size as the detector signals, and may generate malfunctions or indicate the presence of ghost trains. The sources of these voltage peaks are so far unknown. One hypothesis is that they occur when the engine enters or leaves isolated sections of the contact line. This clearly requires further work.

\section{Acknowledgment}

The work presented in this paper was financed by Banverket, Sweden. We would like to thank U. Hellström and R. Byström for raising good questions and giving support to our work.

\section{References}

1 Al Dhalaan, S.M., and Elirbawy, M.A.: 'A quantitative study of the electromagnetic field coupling between the electric power transmission line and railway'. Proc. Canadian Conf. on Electrical and Computer Engineering, May 2003

2 Hill, R.J.: 'Electric railway traction. Part 6 Electromagnetic compatibility-disturbance sources and equipment susceptibility', Power Eng. J., 1997, 11, (1)

3 Ruddle, A.R.: 'Computation of electromagnetic fields in the vicinity of a railway catenary'. Proc. IEE Coll. on EMC in Electric Traction and Signalling, 1995

4 Solbiati, G.L.: 'Managing the EMC between an AC railway line and the external world'. Proc. Electrotech. Conf., May 1996

5 Armstrong, D.S.: 'EMC aspects of electrified railways at high frequencies'. Proc. IEEE Coll. on EMC in Large Systems, 1994

6 Holmes, R.: 'Electromagnetic compatibility of electrified railways' Proc. Int. Conf. on Electric Railways in a United Europe, March 1995

7 Hill, R.J.: 'Electric railway traction. Part 7 Electromagnetic interference in traction systems', Power Eng. J., 1997, 11, (6)

8 Allan, J. et al.: 'Low frequency and radio frequency electromagnetic compatibility for rapid transit railways'. Proc. Fifth European Conf. on Power Electronics and Applications, 1993

9 Banverket research program. (December 2004) [Online]. Available: http://www.banverket.se/upload/pdf/om banverket/fouprogram2.pdf

10 Belden CDT. (December 2004) [Online]. Available: http://www. belden.com/

11 Wisten, А., and Mäkikaltio, P.: 'Methods of measuring electromagnetic emission from trains'. Tech. Report 2002:20, Luleå University of Technology

12 Tellini, B. et al.: 'Conducted and radiated interference measurements in the line-pantograph system', IEEE Trans. Instrum. Meas., 2001, 50, (6)

13 Tukey, J.W.: 'Exploratory data analysis' (Addison-Wesley, 1977)

14 Banverket, Varmgångsdetektorer, Beskrivningar och anvisningar. Varmgångsdetektor 8909, 1993-10-01. Systembeskrivning

15 Benda, S.: 'EMC Undersökning i Kiruna, 2003-06-23-27'. Tech. Report 2004:10, Luleå University of Technology 